\title{
Regulation of persistent activity in hippocampal mossy cells by inhibitory synaptic potentials
}

\author{
Ross W. Anderson ${ }^{1}$ and Ben W. Strowbridge ${ }^{1,2,3}$ \\ ${ }^{1}$ Department of Physiology and Biophysics, ${ }^{2}$ Department of Neurosciences, Case Western Reserve University School \\ of Medicine, Cleveland, Ohio 44106, USA
}

\begin{abstract}
The hippocampal formation receives strong cholinergic input from the septal/diagonal band complex. Although the functional effects of cholinergic activation have been extensively studied in pyramidal neurons within the hippocampus and entorhinal cortex, less is known about the role of cholinergic receptors on dentate gyrus neurons. Using intracellular recordings from rat dentate hilar neurons, we find that activation of ml-type muscarinic receptors selectively increases the excitability of glutamatergic mossy cells but not of hilar interneurons. Following brief stimuli, cholinergic modulation reveals a latent afterdepolarization response in mossy cells that can extend the duration of stimulus-evoked depolarization by $>100$ msec. Depolarizing stimuli also could trigger persistent firing in mossy cells exposed to carbachol or an $\mathrm{ml}$ receptor agonist. Evoked IPSPs attenuated the ADP response in mossy cells. The functional effect of IPSPs was amplified during ADP responses triggered in the presence of cholinergic receptor agonists but not during slowly decaying simulated ADPs, suggesting that modulation of ADP responses by IPSPs arises from destabilization of the intrinsic currents underlying the ADP. Evoked IPSPs also could halt persistent firing triggered by depolarizing stimuli. These results show that through intrinsic properties modulated by muscarinic receptors, mossy cells can prolong depolarizing responses to excitatory input and extend the time window where multiple synaptic inputs can summate. By actively regulating the intrinsic response to synaptic input, inhibitory synaptic input can dynamically control the integration window that enables detection of coincident inputs and shape the spatial pattern of hilar cell activity.
\end{abstract}

Both the dentate gyrus and the hippocampus receive robust cholinergic input from the septum/diagonal band complex (Frotscher et al. 1992; Lübke et al. 1997; Deller et al. 1999). Although previous investigators have examined the functional effect of cholinergic modulation in hippocampal neurons (Halliwell 1990), less is known about the consequences of cholinergic stimulation on dentate gyrus neurons, including hilar neurons, a primary target of cholinergic afferents (Amaral 1978; Frotscher et al. 1992). The dentate hilus contains both excitatory mossy cells (MCs) that project axons large distances ipsilaterally and contralaterally along the septotemporal axis of the hippocampal formation, as well as GABAergic interneurons (Scharfman and Schwartzkroin 1988; Buckmaster et al. 1996; Larimer and Strowbridge 2008). Mossy cells predominately excite granule cells outside of the local region of the dentate gyrus where their soma and dendritic arbor reside (Buckmaster et al. 1996), enabling them to transmit information broadly throughout the hippocampal formation. Periodic discharges in dentate gyrus neurons at theta-band frequencies often are affected by experimental manipulations of cholinergic receptors or projection neurons, though the specific cellular pathways that mediate cholinergic oscillations are unclear. One previous report (Hofmann and Frazier 2010) indicated that activation of muscarinic receptors enabled persistent firing in glutamatergic hilar mossy cells. The specific receptor subtype and the role of cholinergic modulation on subthreshold afterdepolarization (ADP) responses in dentate hilar neurons have not been established.

Here, we examine how inhibitory and cholinergic stimulation interact to regulate the response of dentate hilar neurons to depolarizing stimuli. Although persistent spiking has been

\footnotetext{
${ }^{3}$ Corresponding author

E-mail bens@case.edu

Article is online at http://www.learnmem.org/cgi/doi/10.1101/Im.033829.113.
}

observed in dentate gyrus neurons (Larimer and Strowbridge 2010) and in other brain areas (Egorov et al. 2002; Pressler and Strowbridge 2006), these discharge patterns often require strong initiating stimuli. Enhancing intrinsic excitability by activating muscarinic receptors also enables short depolarizing current steps to trigger persistent firing modes in a wide variety of CNS neurons (Pressler and Strowbridge 2006; Yoshida and Hasselmo 2009; Navaroli et al. 2012; Knauer et al. 2013). Smaller amplitude ADP responses, which do not reach threshold to trigger action potentials (APs), are typically triggered by weaker, and therefore more common, physiological stimuli. Intrinsic mechanisms enable neurons to prolong responses to transient excitatory stimuli. By prolonging the depolarization associated with EPSPs, the intrinsic currents underlying ADP responses extend the window in which multiple EPSPs can summate, relaxing the temporal constraint for coincident inputs to trigger an action potential. The intrinsic conductances that amplify and extend the response to excitatory synaptic input are likely opposed by other mechanisms that diminish depolarizing afterpotentials and terminate persistent firing initiated by brief stimuli. In the dentate gyrus, we find that the functional effect of GABAergic IPSP is enhanced during ADPs, similar to the "inhibitory amplification" known to occur when sustained subthreshold $\mathrm{Na}^{+}$currents are activated (Stuart 1999). Evoked IPSPs also transiently stabilized the membrane potential during ADP responses. The cell type-specificity of $\mathrm{m} 1$ receptormediated cholinergic modulation we find in dentate mossy cells enables transient synaptic stimuli to both start and terminate

2014 Anderson and Strowbridge This article is distributed exclusively by Cold Spring Harbor Laboratory Press for the first 12 months after the full-issue publication date (see http://learnmem.cshlp.org/site/misc/ terms.xhtml). After 12 months, it is available under a Creative Commons License (Attribution-NonCommercial 4.0 International), as described at http://creativecommons.org/licenses/by-nc/4.0/. 
depolarizing afterpotentials, dynamically regulating synaptic integration windows in glutamatergic mossy cells.

\section{Results}

Bath application of carbachol (CCh) $(10 \mu \mathrm{M})$, a broad-spectrum cholinergic receptor agonist, prolonged the depolarizing response of hilar mossy cells to brief step stimuli $(n=62$ of 63 MCs with ADP amplitude $>4 \mathrm{mV}$ tested at $200 \mathrm{msec}$ following step-offset; mean ADP amplitude $=16.6 \pm 0.6 \mathrm{mV}, n=62$ ). With brief stimuli (100- to 250-msec duration depolarizing current steps), the primary effect of cholinergic receptor activation was to convert the normally small afterhyperpolarization (AHP) response in MCs into a large afterdepolarization (ADP) (Fig. 1A). In the example shown in Figure 1A1, bath application of CCh altered the post-step response without affecting the number of action potentials triggered directly by the depolarization pulse (see inset). Over a subset of MCs with similar suprathreshold step responses, CCh significantly increased the ADP amplitude $(P<0.002, n=5)$ (Fig. 1B) without affecting the number of step-evoked APs $(P>0.05)$. The ability of CCh to reveal latent ADP responses was specific to hilar MCs. We found no change in either the step response or afterpotential amplitude following CCh treatment in hilar fast-spiking interneurons $(P>0.05)$ (Fig. 1A,B). These experiments focused on modulatory effects of moderate concentrations of CCh $(10 \mu \mathrm{M})$; we did not determine whether this high degree of cell-type specificity persists when hilar neurons are exposed to high concentrations of cholinergic receptor agonists. The ADP response in MCs did not require spike discharges since weak depolarizing steps that did not evoke APs were effective in triggering ADPs $(n=31$ MCs) (Fig. 1C).

Pirenzepine, a selective antagonist of $\mathrm{m} 1$-class muscarinic receptors (including $\mathrm{m} 1, \mathrm{~m} 3$, and $\mathrm{m} 5$ receptors; $2 \mu \mathrm{M}$ ) (Dörje et al. 1991; Mansfield et al. 2003), reversibly blocked ADP responses triggered by step depolarizations in CCh (mean ADP amplitude reduced from $13.6 \pm 1.4$ to $1.90 \pm 0.6 \mathrm{mV}, 86.1 \%$ reduction, $P<0.001, n=5$ ) (Fig. 2A). By contrast, the m2-class receptor antagonist AF-DX $116(1 \mu \mathrm{M})$ (Gitler et al. 1992) had only small effects on step-evoked ADP responses in the same concentration

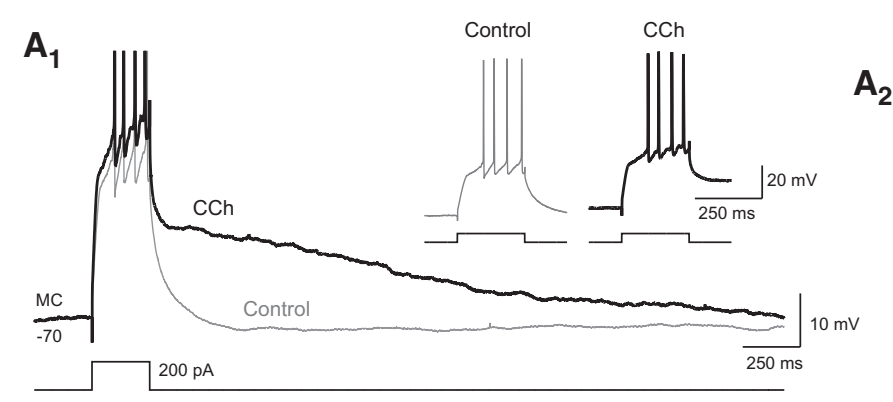

$\mathbf{A}_{2}$
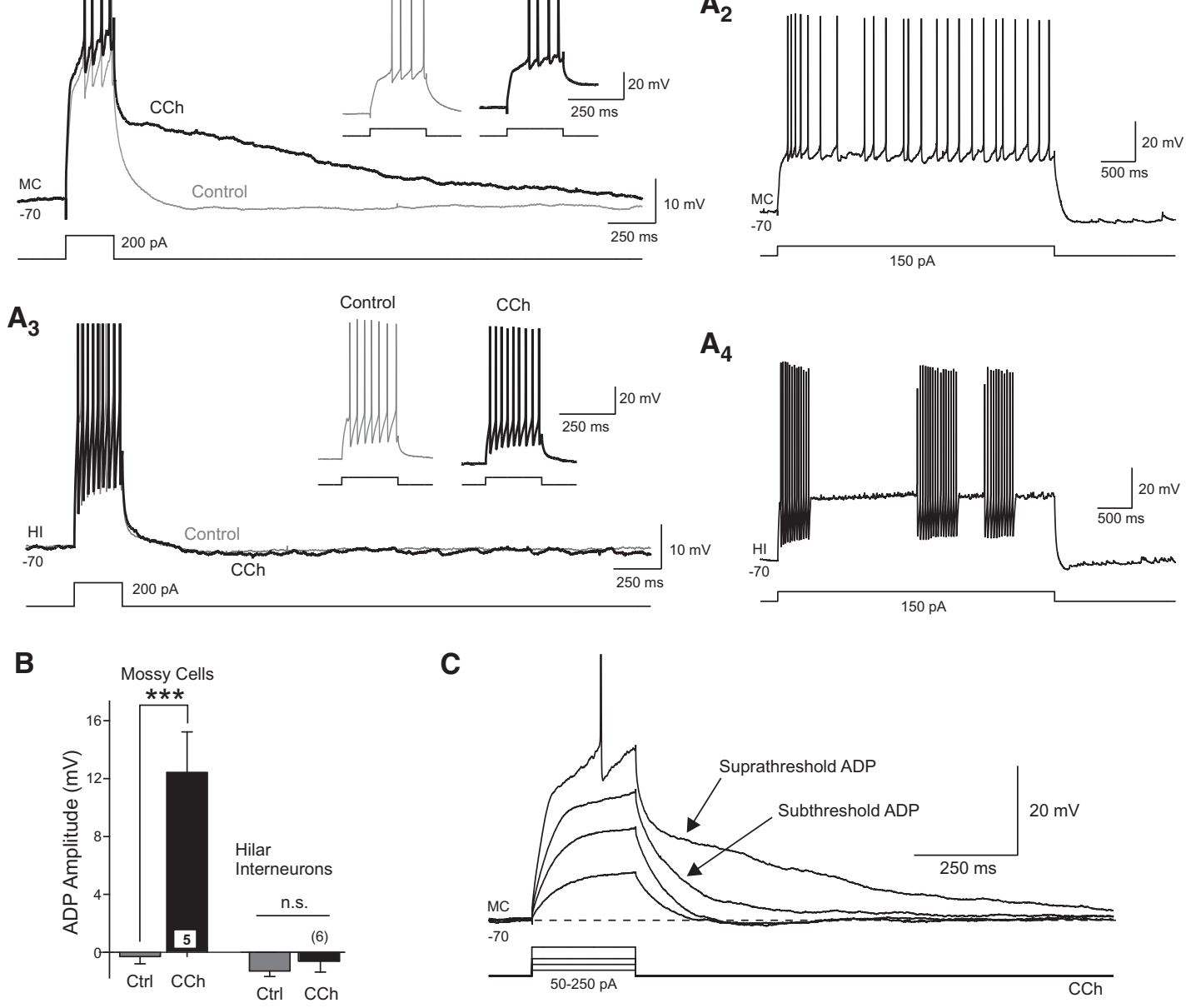

Figure 1. Cholinergic afterdepolarization responses in hilar mossy cells. (A1) Example responses to the same depolarizing step stimuli in control conditions (gray trace) and following bath application of $10 \mu \mathrm{M} \mathrm{CCh}$ (black trace). Enlargements of the step responses shown in the insets. (A2) Response to a long-duration depolarizing step in the same $\mathrm{MC}$ as shown in $A 1$. (A3) Responses of a hilar interneuron (HI) to the same depolarizing current step before and after CCh. Enlargements in insets show step responses. (A4) Intermittent firing response to a long duration current step applied to the same HI shown in $A 3$. (B) Plot of the mean afterpotential amplitude measured 200 msec following step offset in control conditions (gray bars) and following CCh (black bars) in MCs (left) and Hls (right). (***) $P<0.002$, paired $t$-test. (C) Example responses to graded depolarizing steps in a MC in CCh. Both supra- and subthreshold current steps trigger ADP responses in CCh. Action potentials truncated in A1, A3, and C. 

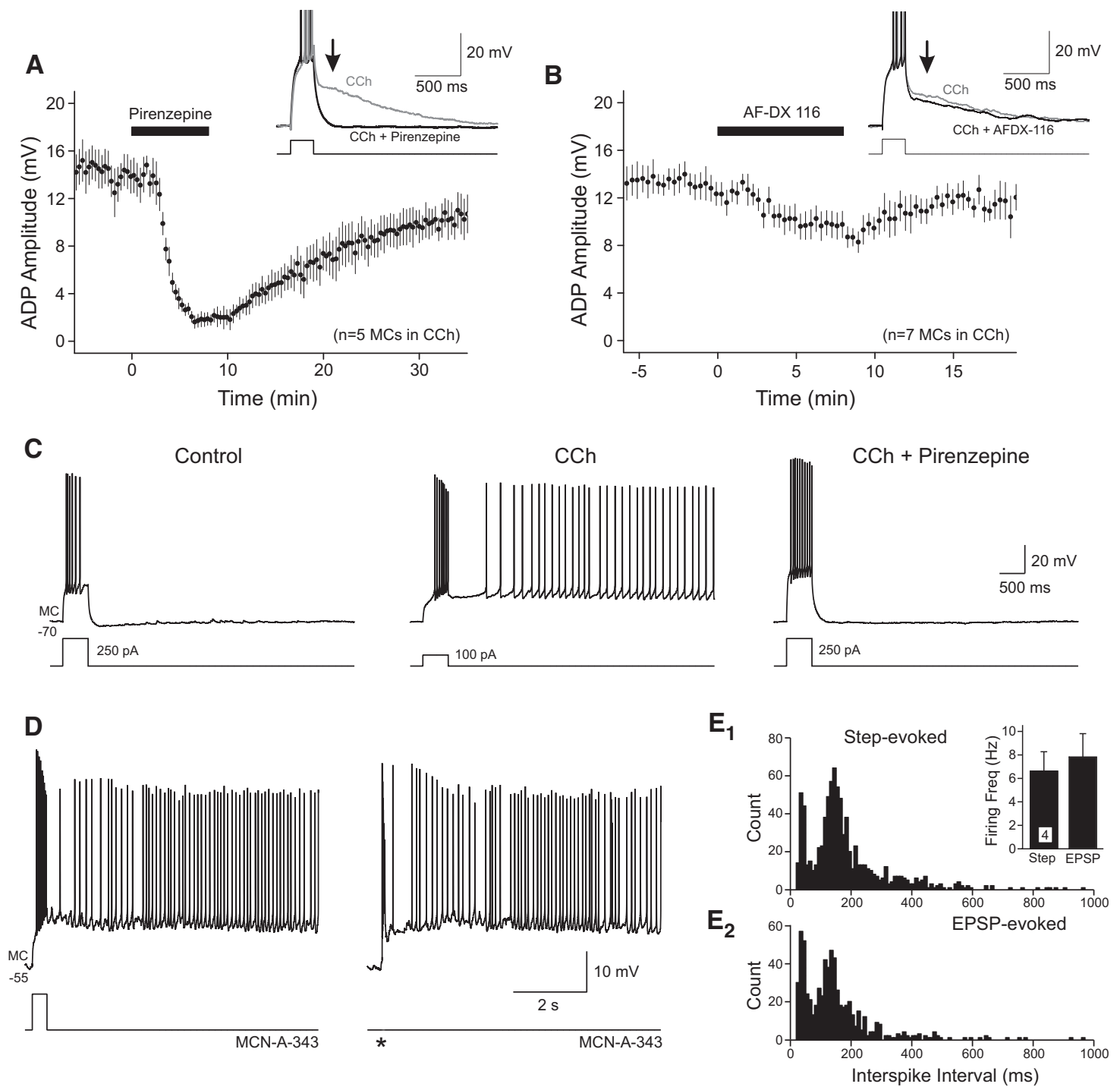

Figure 2. Pharmacology of ADP responses in hilar neurons. (A) Blockade of $\mathrm{m} 1$-class cholinergic receptors with pirenzepine $(2 \mu \mathrm{M})$ reversibly blocked step-evoked ADP responses in CCh. Example responses in CCh before (gray) and after (black) pirenzepine shown in the inset. (B) Blockade of m2-class cholinergic receptors with AF-DX $116(1 \mu \mathrm{M})$ only slightly attenuated ADP responses in CCh. (C) Example of step-triggered persistent firing in CCh blocked by pirenzepine $(2 \mu \mathrm{M})$. (D) Persistent firing triggered by a depolarizing step (left) and synaptic stimulation (right; stimulation time indicated by an asterisk [*]) in the same MC following bath application of $100 \mu \mathrm{M}$ McN-A-343. (E) Plots of inter-spike intervals in persistent firing responses in four MCs treated with McN-A-343. Step depolarization (E1) and synaptic stimulation (E2) triggered similar persistent firing modes. (E1, inset) Similar mean firing frequencies calculated in persistent firing responses triggered by synaptic and step depolarizations $(P>0.05)$. Action potentials truncated in traces shown in insets in $A$ and $B$.

of CCh (29.3\% reduction) (Fig. 2B). Following cholinergic receptor activation, brief depolarizing stimuli often triggered persistent firing modes which were blocked by pirenzepine (Fig. 2C). Also supporting a central role for $\mathrm{m} 1$-class receptors in modulating afterpotentials in mossy cells, we found that McN-A-343, a selective $\mathrm{m} 1$ receptor agonist (Vanderheyden et al. 1990), enabled persistent firing triggered by both step depolarizations and stimulus-evoked EPSPs (Fig. 2D). Similar persistent firing modes were triggered by both step and synaptic stimuli when compared in the same McN-A-343-treated MCs (Fig. 2E). Together, these results suggest that cholinergic stimulation modulates both afterpotentials and enables a persistent firing mode via actions on m1-class muscarinic receptors.

Persistent firing triggered by depolarizing steps following cholinergic receptor activation could be abolished by stepping the membrane to hyperpolarizing potentials for 1-2 sec (Fig. 3A). The ability of transient hyperpolarization to block persistent activity argues that voltage- or intracellular $\mathrm{Ca}^{2+}$-dependent conductances, rather than biochemical modifications of ion channels, underlies plateau generation in MCs. Longer duration hyperpolarizing steps $(2 \mathrm{sec})$ were more likely to abolish persistent firing $(87.5 \pm 7.1 \%$ success rate in blocking persistent firing, $N=7)$ than short steps $(51.7 \pm 15.9 \%$ success rate, $N=5, P<$ $0.05)$, suggesting that reduction in intracellular $\mathrm{Ca}^{2+}$ concentration, rather than simply transient hyperpolarization of the membrane potential, may be the mechanism responsible for blockade of persistent activity. Presumably both ADPs and persistent spiking activity open voltage-gated $\mathrm{Ca}^{2+}$ channels, raising intracellular $\mathrm{Ca}^{2+}$ concentrations and activating $I_{\text {CAN }}$ conductances implicated in MC afterpotentials (Hofmann and Frazier 2010). 

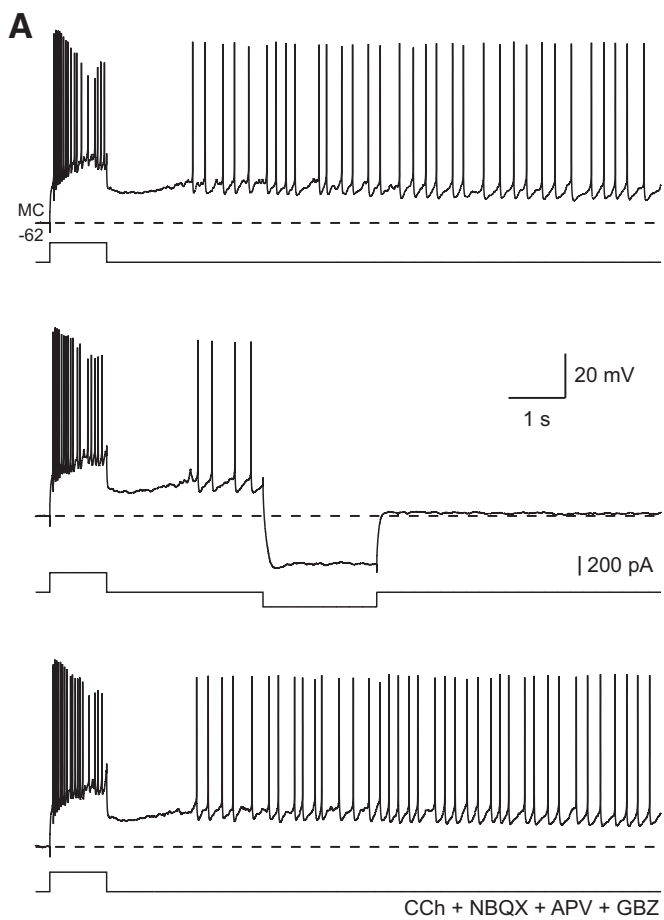

B
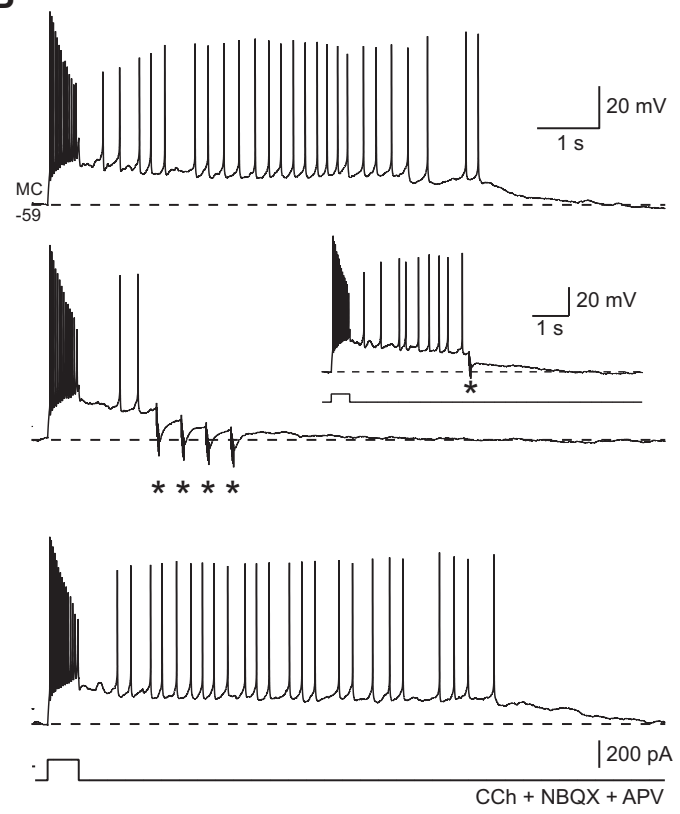

Figure 3. Hyperpolarizing input terminates persistent firing and plateau potentials in hilar mossy cells. (A) Mossy cell persistent firing initiated by a depolarizing step in $10 \mu \mathrm{M}$ CCh was halted by a 150-pA hyperpolarizing step (middle trace). Persistent firing mode was maintained throughout episode in control responses immediately preceding (top) and following (bottom) response with 2 -sec duration hyperpolarizing step. Responses recording following blockade of ionotropic glutamate receptors with APV + NBQX as well as gabazine (GBZ) $(10 \mu \mathrm{M})$ to block GABAA receptors. $(B)$ IPSPs evoked by molecular layer stimulation (repeated bursts of five shocks at $100 \mathrm{~Hz}\left[{ }^{*}\right]$ ) halted persistent firing in a different mossy cell (middle). Control responses without evoked IPSPs acquired immediately before and after example trace are shown in top and bottom traces, respectively. Example of a single evoked IPSP halting persistent firing in the same mossy cell shown in the inset. Fast excitatory synaptic responses blocked with $A P V+N B Q X$ shown in $B$.
The increased effectiveness of 2-sec duration hyperpolarizing steps could result from lower intracellular $\mathrm{Ca}^{2+}$ concentrations achieved after plateau-driven $\mathrm{Ca}^{2+}$ influxes through voltage-gated $\mathrm{Ca}^{2+}$ channels were stopped. Hyperpolarization evoked by inhibitory synaptic potentials also was effective in terminating persistent firing triggered by brief depolarizing current steps (Fig. 3B). Although single IPSPs occasionally abolished persistent firing (Fig. 3B, inset), short bursts of IPSPs (five shocks at $100 \mathrm{~Hz}$ ) could reliably block persistent activity (successful in 12 of 13 MCs tested).

In addition to blocking persistent spiking, IPSPs reduced plateau potentials associated with ADPs in MCs. This effect appeared to be mediated primarily by $\mathrm{GABA}_{\mathrm{A}}$ receptors since gabazine $(10 \mu \mathrm{M})$ eliminated the ability of stimulus evoked responses to modulate the ADP response (six of six experiments). Surprisingly, the attenuating effect of IPSPs on ADPs did not result from the simple summation of hyperpolarizing synaptic potential with the ADP response but, instead, arose from inhibition of the intrinsic currents underlying the ADP itself. We measured how single IPSPs interacted with ADP responses by interleaving ADP only trials with episodes with IPSPs evoked during the ADP decay phase (Fig. 4A). We assayed the change in ADP membrane potential 500 msec after synaptic stimulation, a time point when most of the hyperpolarization directly attributable to the IPSP was dissipated $(9.6 \pm 0.5 \%$ of peak IPSP response remained at $500 \mathrm{msec}$, $N=49$ responses). In eight of eight experiments, we found a larger decline in the ADP membrane potential in trials with IPSPs than predicted from episodes in which the ADP and IPSP responses were evoked in isolation (Fig. 4B; see Materials and Methods for details). Across the group of experiments, single IPSPs decreased the ADP response by $1.2 \pm 0.2 \mathrm{mV}$ beyond the predicted effect of the IPSP ( $P<0.0001$, paired $t$-test, $N=49$ trials from eight experiments). This effect represents an amplification of a single IPSP late response by $190 \pm 31 \%(N=41$ trials, IPSP amplitude calculated 500 msec after IPSP onset).

The supra-additive effect of synaptic inhibition on afterpotentials in MCs was most apparent in trials with large ADPs. In the example shown in Figure $4 \mathrm{C}$, the same depolarizing step response triggered either small $(\sim 10 \mathrm{mV})$ or large $(\sim 14 \mathrm{mV})$ ADPs depending on small differences in the resting membrane potential. Although the episode with a small ADP showed no IPSP amplification effect (Fig. 4C, top), the same stimulus triggered both a prolonged membrane hyperpolarization and attenuation of the larger ADP. We found a statistically significant correlation $(R=0.62, P<0.0001)$ between ADP amplitude and the ability of IPSPs to attenuate ADPs (Fig. 4D). This correlation is unlikely to reflect variation in IPSP amplitudes since the peak amplitude of the IPSP in each ADP + IPSP trial was measured and used to calculate the predicted drop in membrane potential. These results suggest the IPSP amplification during ADPs is voltage-dependent, with supra-additive IPSP effects more likely to occur in ADPs with initial amplitudes larger than $10 \mathrm{mV}$.

Amplifications of IPSPs through interactions with intrinsic voltage-gated currents have been observed in the neocortex (Stuart 1999). In neocortical pyramidal cells, intrinsic subthreshold $\mathrm{Na}^{+}$conductances can enhance and prolong membrane potential responses during IPSPs. In MCs, however, the kinetics of IPSPs are similar whether they are evoked near firing threshold, where IPSP prolongation by voltage-gated $\mathrm{Na}^{+}$conductances should be pronounced (Stuart 1999), or at more hyperpolarized holding potentials (Fig. 5A, inset). Supra-additive IPSP responses in MCs also are unlikely to be mediated by attenuation of window currents through voltage-gated $\mathrm{Ca}^{2+}$ channels (Williams et al. 1997) since that mechanism should also result in different IPSP response kinetics at depolarized and hyperpolarized membrane potentials. 

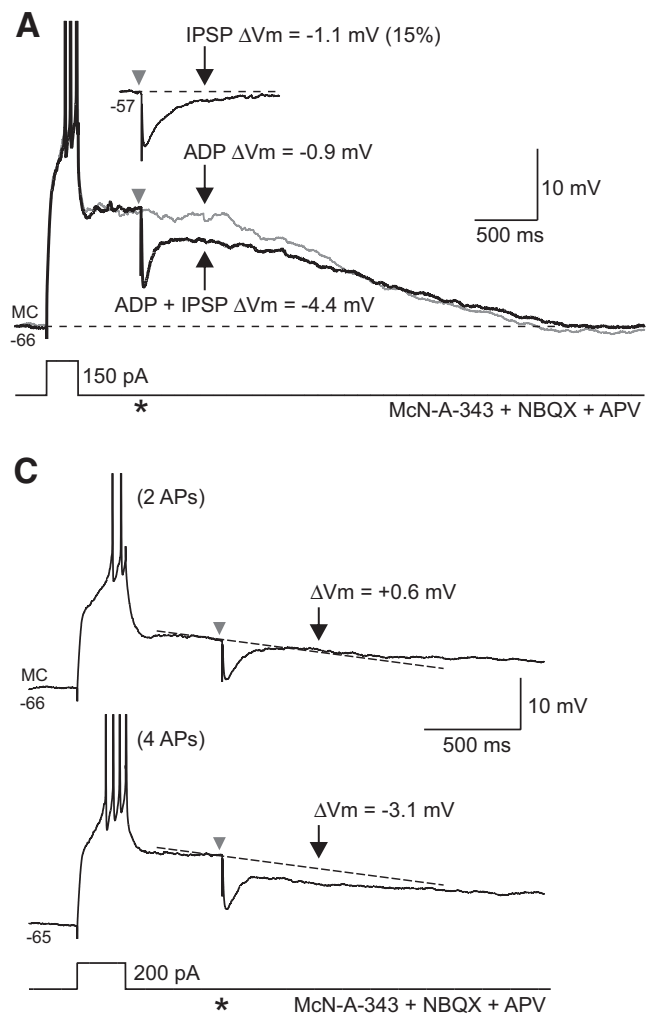

Figure 4. Inhibitory synaptic responses regulate afterdepolarizations in mossy cells. (A) Responses to the same depolarizing step stimuli in a mossy cell exposed to $100 \mu \mathrm{M}$ McN-A-343 and blockers of ionotropic glutamate receptors ( $5 \mu \mathrm{M}$ NBQX and $25 \mu \mathrm{M}$ APV; gray trace). A single IPSP was evoked 500 msec after step offset in one trial (black trace; timing indicated by an asterisk $\left[{ }^{*}\right]$ ). The IPSP decremented the ADP response more than predicted by combining the expected decline in the ADP and IPSP responses evoked in isolation. (Inset) IPSP response recorded at a depolarized membrane potential similar to the peak ADP voltage. Responses measured at times indicated by gray and black arrows. (B) Plot of predicted and actual decrement in the ADP response by single IPSPs evoked $500 \mathrm{msec}$ after step offset, as in $A$, in eight experiments. Lines connect means from each experiment. Symbols at left and right borders represent overall mean \pm SEM from all eight experiments. (***) $P<0.002$, paired $t$-test. (C) Example responses to the same depolarizing step and evoked IPSP stimuli in a mossy cell exposed to McN-A-343 $(100 \mu \mathrm{M})$. In the top response, the current step evoked two APs and a small ADP response which was not affected by the IPSP (predicted $\Delta V \mathrm{~m} \approx$ actual $\Delta \mathrm{Vm}$ ). At a slightly more depolarized membrane potential, the same current step triggered four APs and a large $\mathrm{ADP}$ response that was attenuated by the IPSP (predicted $\Delta \mathrm{Vm}<$ actual $\Delta \mathrm{Vm}$ ). (D) Plot of the relation between ADP amplitude and change in the ADP response evoked by IPSPs in 49 trials from eight MCs. APs truncated in $A$ and $C$.

We conducted a separate series of experiments in control conditions (without cholinergic receptor agonists) in which we forced the membrane potential to slowly decay through "simulated ADP" responses to directly test whether IPSP amplification could result from attenuation of window currents. In both MCs (Fig. 5A) and hilar interneurons (Fig. 5B) depolarized during simulated ADPs, we failed to observe supra-additive effects of evoked IPSPs. Indeed, the actual membrane potential in the majority of simulated ADP trials was more depolarized than predicted. The distributions of actual vs. predicted membrane potential changes in ADPs following $\mathrm{m} 1$ receptor activation and simulated ADPs differed significantly $(P<0.0001$, two-sample Kolmogorov-Smirnov test) (Fig. 5C). The absence of IPSP amplification during simulated ADP responses argues that supra-additive effects arise from disruption of the intrinsic mechanisms underlying the ADP itself.

In addition to attenuating ADPs, GABAergic IPSPs functioned to stabilize the membrane potential during ADP responses. Over repeated trials, ADP responses became more variable as they during ADP responses. The functional effect of IPSPs in mossy cells appeared to result from interaction of inhibitory synaptic potentials and the intrinsic currents supporting the ADP since amplification of IPSPs did not occur on simulated ADPs evoked under control conditions. These results demonstrate that persistent depolarizing responses triggered by excitatory input can be regulated by subsequent inhibitory synaptic input, enabling transient synaptic input to both start and stop regenerative intrinsic responses.

The persistent activity we find induced by cholinergic modulation in mossy cells appears functionally similar to ADPs induced by muscarinic receptor activation in other cortical regions, including entorhinal cortex (Klink and Alonso 1997; Egorov et al. 2002) and neocortex (Schwindt et al. 1988; Krnjević 2004). Activation of muscarinic receptors converts the burst AHP in both mossy cells and entorhinal neurons (Egorov et al. 2002; Hofmann and Frazier 2010) into prolonged depolarizing responses that can trigger persistent firing. The underlying mechanism of depolarizing afterpotentials in mossy cells is likely to be complex, including both calcium-activated inward currents 

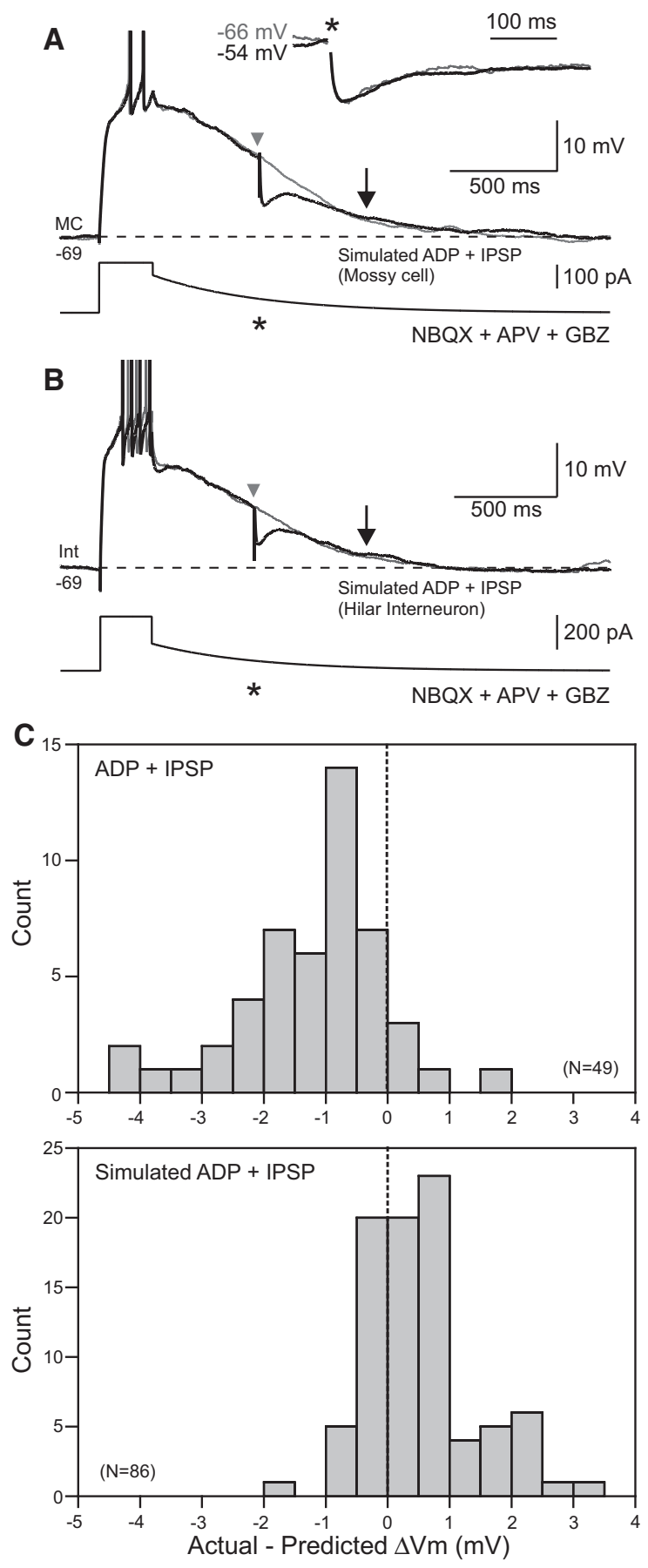

Figure 5. IPSPs do not affect simulated afterdepolarizations. (A) Mossy cell responses to slowly decaying current injection designed to mimic afterdepolarization responses in control conditions. IPSPs evoked during simulated ADPs (black trace, timing indicated by an asterisk [*]) did not decrement the membrane potential beyond the drop predicted by combining the simulated ADP and IPSP responses evoked in isolation. Arrows indicate response time points analyzed. (Inset) Similar kinetics of evoked IPSPs at two different membrane potentials in a different mossy cell. IPSPs scaled to the same peak amplitude. (B) Similar protocol evoked in a hilar interneuron also failed to show an effect of evoked IPSPs on simulated ADPs. APs truncated in $A$ and $B$. (C) Histograms of modulation of real (top) and simulated (bottom) afterdepolarization responses by evoked IPSPs. Values indicated reflect modulation of membrane potential beyond the voltage predicted by analyzing the ADP and IPSP responses evoked in isolation. The two distributions were statistically different $(P<0.0001$, two-sample Kolmogorov-Smirnov test). and voltage-dependent calcium channels. Hofmann and Frazier (2010) found that step-evoked persistent activity in mossy cells following cholinergic stimulation was evident in TTX, required intracellular calcium accumulations, and was attenuated by flufenamic acid, a relatively nonspecific blocker of $I_{\text {CAN }}$ currents in many cell types (Haj-Dahmane and Andrade 1998). Although Hofmann and Frazier (2010) did not explore subthreshold stimuli or ADP responses, our results demonstrate that these weak stimuli were effective in triggering ADPs, consistent with the conclusion that action potentials are not required to generate depolarizing afterpotentials. Moreover, we found that with brief depolarizing stimuli, cholinergic receptor activation converts AHP responses into prolonged ADP responses without affecting the number of action potentials generated by the step response itself (Fig. 1A). Mossy cells have long, complex dendritic arbors that greatly complicate the voltage-clamp analysis of currents necessary to define the molecular mechanism underlying the ADP response. The relatively minor contribution of $\mathrm{Na}^{+}$-based action potentials to the ADP may reflect electrotonically distal locations of critical $\mathrm{Ca}^{2+}$ or voltage-gated conductances. Mossy cells also express both low- and high-threshold voltage-gated calcium currents (Jinno et al. 2003), which are likely to contribute to persistent depolarizing responses. Without novel, more selective, pharmacological methods to define the calcium-dependent inward current already implicated in the mossy cell ADP response (Hofmann and Frazier 2010), it remains challenging to fully dissect the molecular mechanism underlying persistent activity in these neurons.

The functional effects of cholinergic stimulation in the dentate gyrus have remarkable cell type specificity. Our results support earlier work that showed that broad-spectrum cholinergic receptor agonists increase the excitability of glutamatergic mossy cells without dramatically affecting responses to depolarizing stimuli in nearby GABAergic hilar interneurons (Hofmann and Frazier 2010). The present study extends that finding to include both subthreshold ADP responses as well as persistent firing and also defines the muscarinic receptor subtype that modulates excitability in mossy cells. The greater effectiveness we found of the $\mathrm{m} 1 \mathrm{R}$ - over $\mathrm{m} 2 \mathrm{R}$-class cholinergic blockers, as well as the positive result with the $\mathrm{m} 1 \mathrm{R}$ agonist McN-A-343, suggests that ADPs were recruited through actions on $\mathrm{m} 1$ (or $\mathrm{m} 3 / \mathrm{m} 5$ ) receptors. The weak blockade of ADPs by AFDX-116 is consistent with the moderate (125-750 nM) (Gitler et al. 1992; Billard et al. 1995; Mansfield et al. 2003) affinity of this m2-selective agent for m1-class receptors. Our results also are consistent with ultrastructural work (Deller et al. 1999) demonstrating that choline acetyltransferase (ChAT)-positive boutons contact mossy cell somata and proximal dendrites. Cholinergic afferents to the dentate hilus arise from the medial septum/diagonal band complex (Frotscher et al. 1992; Lübke et al. 1997), a projection often associated with theta-band oscillations (Yoder and Pang 2005). A previous in vitro study (Chiang et al. 2010) found that cholinergic stimulation increased the excitability of basket cells in the dentate gyrus, also through a m1-class receptor, suggesting that different interneuron subtypes in the dentate gyrus are likely to be heterogeneous in their modulatory mechanisms. The selective increase in subthreshold excitability we find following $\mathrm{m} 1$ receptor activation in mossy cells but not hilar interneurons may enable the synaptic integration window associated with theta oscillations to be extended in principal cells while retaining short-duration integration windows in nearby GABAergic interneurons. Modulation of synaptic integration timing in excitatory neurons may be necessary if hilar interneurons function to help maintain network oscillations which could be disrupted following changes in their intrinsic excitability. The prolongation of depolarizing responses by intrinsic currents recruited following $\mathrm{m} 1$ receptor activation may also enable mossy cells to regulate the temporal window 

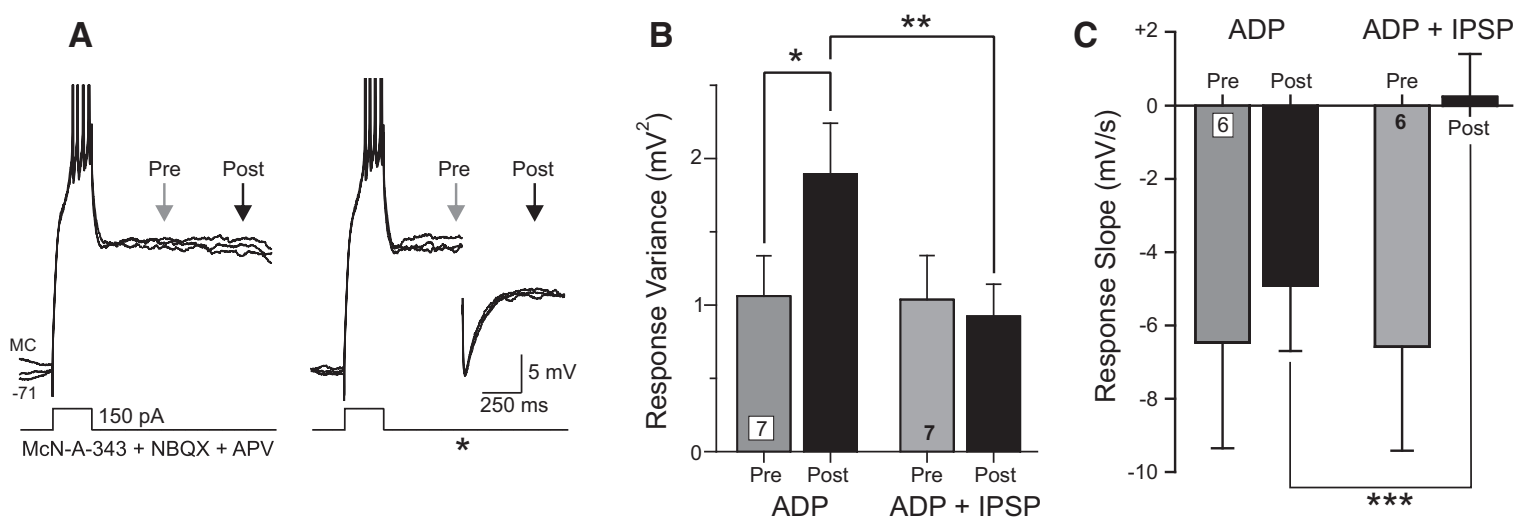

Figure 6. IPSPs function to stabilize the membrane potential and reduce ADP variability. (A) Set of three example responses to a depolarizing step stimulus showing increase in membrane potential variability as the ADP begins to decay (left). IPSPs reduce the increase in ADP variability (right). APs truncated. (B) Plot of increase in ADP variability with time in seven experiments (gray and black bars). IPSP trials show no increase in ADP variance (gray and black bars). $\left(^{*}\right) P<0.05,\left({ }^{* *}\right) P<0.02$, both paired $t$-test. (C) Plot of membrane potential slope calculated over 200 msec at two segments during the ADP response (segment end points indicated by arrows in $A$ ) in interleaved trials with and without IPSPs. $\left.{ }^{* * *}\right) P<0.01$, paired $t$-test.

required for near-coincident EPSPs to trigger spiking. Presumably by attenuating ADP responses, inhibitory inputs could regulate the degree of temporal precision required for clusters of asynchronous EPSPs to trigger action potentials.

Our results are likely related to other studies demonstrating bistability mediated by intrinsic conductances, both under control conditions in vitro (Williams et al. 1997; Pressler and Strowbridge 2006; Larimer and Strowbridge 2010) and following cholinergic stimulation (Schwindt et al. 1988; Krnjević 2004). Following extensive blockade of voltage-gated $\mathrm{K}^{+}$and $\mathrm{Na}^{+}$currents, cortical pyramidal cells (Reuveni et al. 1993) and spinal motoneurons (Carlin et al. 2009) exhibit prolonged regenerative depolarizations that outlast brief triggering steps and decay in a stepwise manner. Hyperpolarizing pulses can trigger stepwise decays under these conditions, raising the possibility that inhibitory synaptic input could turn off regenerative inward currents mediated by spatially restricted clusters of voltage-gated $\mathrm{Ca}^{2+}$ channels in an all-or-none fashion (Major and Tank 2004). Egorov et al. (2002) also found that hyperpolarizing current steps could reduce the frequency of, or terminate, stable persistent firing modes.

Our results demonstrate that synaptic inhibition can modulate both subthreshold ADPs and persistent spiking activity, enabling the duration of sustained depolarizing responses to be actively regulated. These results are related to prior studies that showed IPSPs could be "amplified" when they interact with sustained inward currents, such as subthreshold $\mathrm{Na}^{+}$current (Stuart 1999). In mossy cells, the functional effect of synaptically evoked IPSPs also was enhanced when they occurred during ADPs, leading to a sustained attenuation (or termination) of the afterpotential. In the spinal cord, activation of $\mathrm{GABA}_{\mathrm{B}}$ receptors with exogenous baclofen diminished stimulus-evoked plateau potentials (Russo et al. 1998). The rapid IPSP kinetics we find following transient stimulation in the dentate hilus are consistent with activation primarily of $\mathrm{GABA}_{\mathrm{A}}$ receptors; presumably these ionotropic receptors are able to effect more precise temporal control over the ADP response than slower $\mathrm{GABA}_{\mathrm{B}}$ receptor-mediated IPSPs. Multiple cellular mechanisms may underlie the ability of synaptic IPSPs to attenuate ADP responses in dentate mossy cells. These include modulation of intracellular $\mathrm{Ca}^{2+}$ concentration, a pathway implicated in computational models of persistent activity in entorhinal (Fransén et al. 2002, 2006) and olfactory bulb (Inoue and Strowbridge 2008) neurons, and effects on voltage-gated ion channels modulated by muscarinic receptors. In entorhinal neurons exposed to cholinergic receptor agonists, stable persistent firing modes can be disrupted both by excitatory stimuli (Tahvildari et al. 2007, 2008) and by hyperpolarizing current steps (Egorov et al. 2002), suggesting that persistent firing may require relatively specific conditions, such as a narrow range of intracellular $\mathrm{Ca}^{2+}$ concentrations (Fransén et al. 2006).

Both the present results in the dentate gyrus and prior work in spinal neurons (Russo et al. 1998) highlight the importance of nonsubtractive forms of synaptic inhibition that mediate large functional changes through interactions with intrinsic conductances. By regulating intrinsic depolarizing responses, inhibitory synaptic input can directly control the duration of the cellautonomous "memory" of brief depolarizing inputs generated in hilar mossy cells. Although intrinsic ADP responses (and persistent firing modes) also can be regulated by varying cholinergic synaptic tone, this mechanism is unlikely to be rapid enough to terminate specific responses. Inhibitory regulation of the prolongation of responses triggered by depolarizing stimuli, by contrast, enables fine temporal control over the duration of individual response without affecting overall neuronal excitability. The striking cell type specificity of the IPSP-sensitive ADP response in the dentate gyrus may enable synchronous activity of interneuron ensembles to set the maximal duration of sustained depolarizations triggered by excitatory synaptic input. Given the propensity of GABAergic interneurons in the hippocampal formation to discharge rhythmically (Buzsáki 2002; Yoder and Pang 2005), the functional role of IPSP-regulated ADPs may be to dynamically extend and control the EPSP integration window within individual cycles of the network oscillation.

\section{Materials and Methods}

Horizontal brain slices containing the ventral hippocampus and dentate gyrus from P14-20 Sprague-Dawley rats of either sex were prepared using a Leica VT1200 vibratome as described previously (Larimer and Strowbridge 2008, 2010). Artificial cerebrospinal fluid (ACSF) solution with low $\left[\mathrm{Ca}^{2+}\right]$ was used when preparing and storing slices that contained (in mM): $124 \mathrm{NaCl}$, $2.6 \mathrm{KCl}, 1.23 \mathrm{NaH}_{2} \mathrm{PO}_{4}, 3 \mathrm{MgSO}_{4}, 26 \mathrm{NaHCO}_{3}, 10$ dextrose, 1 $\mathrm{CaCl}_{2}$, equilibrated with $95 \% \mathrm{O}_{2} / 5 \% \mathrm{CO}_{2}$. The ACSF was chilled to $4^{\circ} \mathrm{C}$ during slicing. Hippocampal slices were incubated at $30^{\circ} \mathrm{C}$ for $30 \mathrm{~min}$ and then maintained at room temperature. Brain slices were superfused during experiments with ACSF that contained (in mM): $124 \mathrm{NaCl}, 3 \mathrm{KCl}, 1.23 \mathrm{NaH}_{2} \mathrm{PO}_{4}, 1.2 \mathrm{MgSO}_{4}$, 
$26 \mathrm{NaHCO}_{3}, 10$ dextrose, $2.5 \mathrm{CaCl}_{2}$, equilibrated with $95 \% \mathrm{O}_{2} / 5 \%$ $\mathrm{CO}_{2}$ and warmed to $30^{\circ} \mathrm{C}$. Except where noted, all compounds used in this study were obtained from Sigma. Glutamate receptor (NBQX and APV) and $\mathrm{GABA}_{\mathrm{A}}$ receptor antagonists (gabazine) were purchased from Tocris.

Whole-cell current-clamp recordings were made from dentate hilar neurons visualized with infrared-differential interference contrast (IR-DIC) optics using an Axioskop 1 FS (Carl Zeiss) fixed-stage upright microscope and Axopatch 1D amplifier (Molecular Devices). Electrodes used for whole-cell recordings (3$6 \mathrm{M} \Omega$ ) were pulled from thin-wall capillary tubes with filament (1.5-mm OD, WPI) and contained (in mM): $140 \mathrm{~K}$-methylsulfate (MP Biochemicals), $4 \mathrm{NaCl}, 10$ HEPES, 0.2 EGTA, 4 MgATP, $0.3 \mathrm{Na}_{3} \mathrm{GTP}, 10$ Tris-phosphocreatine. Intracellular recordings were low-pass filtered at $2 \mathrm{kHz}$ and sampled at $5 \mathrm{kHz}$ using a 16-bit analog-to-digital converter (ITC-18, Instrutech/Heka) using custom software written in Visual Basic.NET (Microsoft) and Matlab (Mathworks). Origin 8.5 (OriginLab) and custom Matlab routines were used to analyze data. Pharmacological agents were applied by switching the perfusion solution. Synaptic potentials were evoked using sharpened tungsten monopolar electrodes (FHC) placed in either the molecular layer or hilus of the dentate gyrus and activated using a constant-current stimulus isolation unit (A 360, WPI). Mossy cells and hilar interneurons were distinguished based on established intrinsic properties (spike clustering fraction and mean spike time) that have been validated in monosynaptically coupled paired recordings between different hilar cell types under the same conditions as in the present study (Larimer and Strowbridge 2008).

Predicted changes in ADP membrane potential from evoked IPSP were calculated by summing the voltage change during ADP responses evoked in 4-6 trials without IPSPs with the estimated membrane potential change resulting from the IPSP itself. The IPSP component was calculated by first computing the average percentage of the peak IPSP response that remains at the time point assayed from evoked IPSPs in trials without ADPs. The peak IPSP amplitude in ADP + IPSP trials was scaled by this percentage to generate the voltage change expected from the IPSP at the time point assayed (typically $500 \mathrm{msec}$ after the IPSP was evoked). For example, if a stimulus evoked an IPSP with a peak amplitude of $10 \mathrm{mV}$ and had decayed to $2 \mathrm{mV}$ after $500 \mathrm{msec}$ in trials without step-evoked ADPs, it would be assumed to generate $20 \%$ of its peak response after $500 \mathrm{msec}$ in trials with ADPs. Predicted changes in ADP voltage were compared to actual voltage changes assayed at the same time points in trials with both step-evoked ADPs and IPSPs. By utilizing interleaved trials with different stimulus combinations, we minimize uncertainties associated with estimates of the IPSP contribution to the ADP decay. Voltage slopes during phases of the ADP response were calculated over 40-msec duration windows from the average of the four most stable trials in each condition (ADP or ADP + IPSP). Voltages presented are not corrected for the liquid junction potential. Statistical significance was determined using the Student's $t$-test unless specified otherwise. Data are presented as mean \pm SEM.

\section{Acknowledgments}

We thank Drs. Roberto Galan and Phil Larimer for helpful discussions and Dr. Todd Pressler for critical comments on this manuscript. This study was supported by NIH grants R01-DC04285 and R01-DC09948 to B.W.S.

\section{References}

Amaral DG. 1978. A Golgi study of cell types in the hilar region of the hippocampus in the rat. J Comp Neurol 182: 851-914.

Billard W, Binch H III, Crosby G, McQuade RD. 1995. Identification of the primary muscarinic autoreceptor subtype in rat striatum as $\mathrm{m} 2$ through a correlation of in vivo microdialysis and in vitro receptor binding data. J Pharmacol Exp Ther 273: 273-279.

Buckmaster PS, Wenzel HJ, Kunkel DD, Schwartzkroin PA. 1996. Axon arbors and synaptic connections of hippocampal mossy cells in the rat in vivo. J Comp Neurol 366: 271-292.
Buzsáki G. 2002. Theta oscillations in the hippocampus. Neuron 33: $325-340$.

Carlin KP, Bui TV, Dai Y, Brownstone RM. 2009. Staircase currents in motoneurons: insight into the spatial arrangement of calcium channels in the dendritic tree. J Neurosci 29: 5343-5353.

Chiang PH, Yeh WC, Lee CT, Weng JY, Huang YY, Lien CC. 2010. M1-like muscarinic acetylcholine receptors regulate fast-spiking interneuron excitability in rat dentate gyrus. Neuroscience 169: 39-51.

Deller T, Katona I, Cozzari C, Frotscher M, Freund TF. 1999. Cholinergic innervation of mossy cells in the rat fascia dentata. Hippocampus 9: 314-320.

Dörje F, Wess J, Lambrecht G, Tacke R, Mutschler E, Brann MR. 1991. Antagonist binding profiles of five cloned human muscarinic receptor subtypes. J Pharmacol Exp Ther 256: 727-733.

Egorov AV, Hamam BN, Fransén E, Hasselmo ME, Alonso AA. 2002. Graded persistent activity in entorhinal cortex neurons. Nature 420: $173-178$.

Fransén E, Alonso AA, Hasselmo ME. 2002. Simulations of the role of the muscarinic-activated calcium-sensitive nonspecific cation current INCM in entorhinal neuronal activity during delayed matching tasks. J Neurosci 22: $1081-1097$.

Fransén E, Tahvildari B, Egorov AV, Hasselmo ME, Alonso AA. 2006. Mechanism of graded persistent cellular activity of entorhinal cortex layer V neurons. Neuron 49: 735-746.

Frotscher M, Soriano E, Leranth C. 1992. Cholinergic and GABAergic neurotransmission in the fascia dentata: electron microscopic immunocytochemical studies in rodents and primates. Epilepsy Res Suppl 7: $65-78$.

Gitler MS, Reba RC, Cohen VI, Rzeszotarski WJ, Jin B, Baumgold J. 1992. A novel $\mathrm{m} 2$-selective muscarinic antagonist: binding characteristics and autoradiographic distribution in rat brain. Brain Res 582: 253-260.

Haj-Dahmane S, Andrade R. 1998. Ionic mechanism of the slow afterdepolarization induced by muscarinic receptor activation in rat prefrontal cortex. J Neurophysiol 80: 1197-1210.

Halliwell JV. 1990. Physiological mechanisms of cholinergic action in the hippocampus. Prog Brain Res 84: 255-272.

Hofmann ME, Frazier CJ. 2010. Muscarinic receptor activation modulates the excitability of hilar mossy cells through the induction of an afterdepolarization. Brain Res 1318: 42-51.

Inoue T, Strowbridge BW. 2008. Transient activity induces a long-lasting increase in the excitability of olfactory bulb interneurons. J Neurophysiol 99: 187-199.

Jinno S, Ishizuka S, Kosaka T. 2003. Ionic currents underlying rhythmic bursting of ventral mossy cells in the developing mouse dentate gyrus. Eur J Neurosci 17: 1338-1354.

Klink R, Alonso A. 1997. Muscarinic modulation of the oscillatory and repetitive firing properties of entorhinal cortex layer II neurons. J Neurophysiol 77: 1813-1828.

Knauer B, Jochems A, Valero-Aracama MJ, Yoshida M. 2013. Long-lasting intrinsic persistent firing in rat CA1 pyramidal cells: a possible mechanism for active maintenance of memory. Hippocampus 23: $820-831$.

Krnjević K. 2004. Synaptic mechanisms modulated by acetylcholine in cerebral cortex. Prog Brain Res 145: 81-93.

Larimer P, Strowbridge BW. 2008. Nonrandom local circuits in the dentate gyrus. J Neurosci 28: 12212-12223.

Larimer P, Strowbridge BW. 2010. Representing information in cell assemblies: persistent activity mediated by semilunar granule cells. Nat Neurosci 13: 213-222.

Lübke J, Deller T, Frotscher M. 1997. Septal innervation of mossy cells in the hilus of the rat dentate gyrus: an anterograde tracing and intracellular labeling study. Exp Brain Res 114: 423-432.

Major G, Tank D. 2004. Persistent neural activity: prevalence and mechanisms. Curr Opin Neurobiol 14: 675-684.

Mansfield KJ, Mitchelson FJ, Moore KH, Burcher E. 2003. Muscarinic receptor subtypes in the human colon: lack of evidence for atypical subtypes. Eur J Pharmacol 482: 101-109.

Navaroli VL, Zhao Y, Boguszewski P, Brown TH. 2012. Muscarinic receptor activation enables persistent firing in pyramidal neurons from superficial layers of dorsal perirhinal cortex. Hippocampus 22: 1392-1404.

Pressler RT, Strowbridge BW. 2006. Blanes cells mediate persistent feedforward inhibition onto granule cells in the olfactory bulb. Neuron 49: $889-904$.

Reuveni I, Friedman A, Amitai Y, Gutnick MJ. 1993. Stepwise repolarization from $\mathrm{Ca}^{2+}$ plateaus in neocortical pyramidal cells: evidence for nonhomogeneous distribution of $\mathrm{HVA} \mathrm{Ca}^{2+}$ channels in dendrites. J Neurosci 13: 4609-4621.

Russo RE, Nagy F, Hounsgaard J. 1998. Inhibitory control of plateau properties in dorsal horn neurones in the turtle spinal cord in vitro. J Physiol 506: 795-808.

Scharfman HE, Schwartzkroin PA. 1988. Electrophysiology of morphologically identified mossy cells of the dentate hilus recorded in guinea pig hippocampal slices. J Neurosci 8: 3812-3821. 
Schwindt PC, Spain WJ, Foehring RC, Chubb MC, Crill WE. 1988 Slow conductances in neurons from cat sensorimotor cortex in vitro and their role in slow excitability changes. J Neurophysiol 59: $450-467$.

Stuart G. 1999. Voltage-activated sodium channels amplify inhibition in neocortical pyramidal neurons. Nat Neurosci 2: $144-150$.

Tahvildari B, Fransén E, Alonso AA, Hasselmo ME. 2007. Switching between "On" and "Off" states of persistent activity in lateral entorhinal layer III neurons. Hippocampus 17: 257-263.

Tahvildari B, Alonso AA, Bourque CW. 2008. Ionic basis of ON and OFF persistent activity in layer III lateral entorhinal cortical principal neurons. J Neurophysiol 99: 2006-2011.

Vanderheyden P, Gies JP, Ebinger G, De Keyser J, Landry Y, Vauquelin G. 1990. Human M1-, M2- and M3-muscarinic cholinergic receptors: binding characteristics of agonists and antagonists. J Neurol Sci 97: 67-80.

Williams SR, Tóth TI, Turner JP, Hughes SW, Crunelli V. 1997. The "window" component of the low threshold $\mathrm{Ca}^{2+}$ current produces input signal amplification and bistability in cat and rat thalamocortical neurones. J Physiol 505: 689-705.

Yoder RM, Pang KCH. 2005. Involvement of GABAergic and cholinergic medial septal neurons in hippocampal theta rhythm. Hippocampus 15: 381-392.

Yoshida M, Hasselmo ME. 2009. Persistent firing supported by an intrinsic cellular mechanism in a component of the head direction system. J Neurosci 29: 4945-4952.

Received November 5, 2013; accepted in revised form February 10, 2014. 


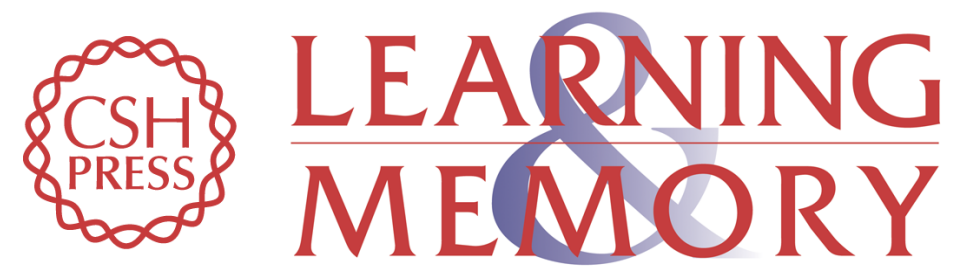

\title{
Regulation of persistent activity in hippocampal mossy cells by inhibitory synaptic potentials
}

\author{
Ross W. Anderson and Ben W. Strowbridge
}

Learn. Mem. 2014, 21:

Access the most recent version at doi:10.1101/Im.033829.113

\begin{aligned} & \hline References $\begin{array}{l}\text { This article cites } 39 \text { articles, } 8 \text { of which can be accessed free at: } \\ \text { http://learnmem.cshlp.org/content/21/5/263.full.html\#ref-list-1 }\end{array} \\ & \begin{array}{r}\text { Creative } \\ \text { Commons } \\ \text { License }\end{array} \begin{array}{l}\text { This article is distributed exclusively by Cold Spring Harbor Laboratory Press for the } \\ \text { first } 12 \text { months after the full-issue publication date (see } \\ \text { http://learnmem.cshlp.org/site/misc/terms.xhtml). After } 12 \text { months, it is available under } \\ \text { a Creative Commons License (Attribution-NonCommercial } 4.0 \text { International), as } \\ \text { described at http://creativecommons.org/licenses/by-nc/4.0/. }\end{array} \\ & \begin{array}{c}\text { Receive free email alerts when new articles cite this article - sign up in the box at the } \\ \text { top right corner of the article or click here. }\end{array} \\ & \begin{array}{c}\text { Service } \\ \text { terting }\end{array}\end{aligned}$

